\title{
Preparation and Characterization of Activated Carbon from Reedy Grass Leaves in a Two- Step Activation Procedure
}

\author{
Xu Jianzhong, Chen Lingzhi,Feng Xiaojie \\ College of Chemistry and Environmental Science \\ HeBei University \\ Baoding, China \\ xjz8112@sina.com
}

\author{
Chen Lingzhi \\ Department of Applied Chemistry \\ HengShui University \\ Hengshui, China \\ chenlingzhi80@126.com
}

\begin{abstract}
Activated carbons (AC) were produced by chemical activation with potassium hydroxide $(\mathrm{KOH})$ at $800^{\circ} \mathrm{C}$ from chars that were carbonized from reedy grass leaves at $450^{\circ} \mathrm{C}$ in $\mathrm{N}_{2}$ atmosphere and their characteristics were investigated. The effects of activation temperature, duration time and impregnation time were examined. Adsorption capacity was demonstrated with BET and iodine number. BET surface area, pore volume and pore size of activated carbons were characterized by $\mathrm{N}_{2}$ adsorption isotherms. The maximum surface area and iodine number of the $\mathrm{AC}$ was $1100 \mathrm{~m}^{2} / \mathrm{g}$ and $1080 \mathrm{mg} / \mathrm{g}$ produced at $800^{\circ} \mathrm{C}$ for $2 \mathrm{~h}$ and impregnation time is 8h.The surface chemical characteristics of activated carbons were determined by FT-IR method. The microstructure of the produced activated carbons was examined by scanning electron microscopy (SEM). Thermal gravimetry (TG) analysis of raw material was carried out.
\end{abstract}

Keywords-Activated carbons; КОН activation; Reedy grass; Pore properties

\section{INTRODUCTION}

Activated carbon is one of the most widely used adsorbents because of its high adsorptive capacity. Therefore, it has been widely used as a kind of adsorbent and in catalysis or separation processes. As a result, the demand for activated carbon is increasing. However, activated carbon is expensive which limits its large-scale application. A potential method to reduce its cost is to produce activated carbon from low-cost materials such as agricultural products [1].

In recent years, a lot of researches have been reported on activated carbons from agricultural wastes, such as cherry stones[2], vine shoots [3] ,spirit lees[4]coconut shells [5], corncob[6] candlenut shell[7], pecan shells [8], cotton stalks[9], hazelnut shell[10], olive stone[11], rice bran [12], husk[13], pineapple peel[14] and globe artichoke[15] .et al.

Reedy grass is a kind of plant growing abundantly in Northem China's Hebei province. The herbaceous plant can generate a lot of leafy wastes that could be efficiently and sustainably valorized. The aim of this work is to study the ability of reedy grass leaves to serve as a precursor for an efficient activated carbon. In addition, potassium hydroxide which is commonly used for the preparation of carbon adsorbents from lignocellulosic products gives the possibility to develop microporous and/or mesoporous carbon with a specific surface area depending on the temperature of activation. However, the activation of reedy grass leaves with $\mathrm{KOH}$ in a two-step activation procedure have not yet been reported so far.. The study covers the effect of operating parameters, such as the time and temperature of activation and impregnation time on the product quality. The product quality is characterized based on the BET and iodine number. The development of pore characteristics of activated carbon is examined with effects of activation temperature and duration time and impregnation time.

\section{EXPERIMENTAL}

\section{A. Preparation of Activated Carbon}

Reedy grass leaves from Hengshui Lake (HeBei province) were washed with distilled water to remove the impurities (dust and water soluble substances) and dried at $110{ }^{\circ} \mathrm{C}$ for $24 \mathrm{~h}$, and sieved to obtain particles size lower than 80 mesh prior to their activations.

We adopted a two-step activation procedure (first pre carbonizing the reedy grass then impregnating the chemical activator-alkali with the pre-carbonized char[16]) . The char that was prepared from pre-carbonizing reedy grass leaves was prepared by the following procedures: the dried reedy grass leaves was carbonized at $450{ }^{\circ} \mathrm{C}$ for $2 \mathrm{~h}$ in a nitrogen gas environment. In a typical two-step activation process, pre-carbonized char was soaked with $\mathrm{KOH}$ solutions at a concentration of $3 \mathrm{~mol} / 1$ for $6,8,10,12 \mathrm{~h}$ at room temperature. These char containing solutions were then treated at room temperature. Afterwards, the chars were separated by filtration and activated at different temperatures for $1,2,3.4 \mathrm{~h}$ respectively. After the activation, all the samples were washed with hot distilled water. This was continued until the $\mathrm{pH}$ value of the washing effluent reached approximately 7. The wet samples were filtered, then dried at $105^{\circ} \mathrm{C}$ overnight.

\section{B. Iodine Test}

The iodine number is a technique employed to determine the adsorption capacity of activated carbons. The iodine number indicates the porosity of the activated carbon and it is defined as the amount of iodine adsorbed by $1 \mathrm{~g}$ of carbon at the mg level. Iodine number can be used as an approximation for surface area and microporosity of active carbons with good precision.

\section{C. $\mathrm{N}_{2}$ Adsorption-Desorption at $-196^{\circ} \mathrm{C}$}

Characterization of obtained activated carbons was 
determined by nitrogen adsorption at $-196^{\circ} \mathrm{C}$ with surface area and pore size analyzer (TriStar II 3020, Micromeritics). Before analysis, all of the obtained ACs were evacuated under vacuum condition at $180^{\circ} \mathrm{C}$ over night in order to clean all the pores.

\section{Thermogravimetric Analysis}

Thermogravimetric analysis was performed by using a 209F3 (NETZSCH) with simultaneous recording ofTG curves in relation to temperature and time (heating rate: $10{ }^{\circ} \mathrm{C} / \mathrm{min}$, temperature range: $30-800^{\circ} \mathrm{C}$, sample mass: $7 \mathrm{mg})$.

\section{E. Infrared Spectroscopy}

Infrared transmittance measurements of the activated carbons were carried out on a Varian 640FT-IR spectrometer at room temperature in the $400-4000 \mathrm{~cm}^{-1}$ wave number range.

\section{F. Morphological Structure}

SEM (Hitachi High-Technologies Co., Japan) was carried out to show the pore structure of obtained activated carbons.

\section{RESULTS AND DISCUSSION}

\section{A. Effect of Activating Temperature, Duration and Impregnation Time}

As seen in Table 1, an increase in the BET surface area and iodine number is observed with increase in activation time up to $2 \mathrm{~h}$ for activation temperature from $650-800^{\circ} \mathrm{C}$. The BET surface area and iodine number at the impregnation time of $8 \mathrm{~h}, 800^{\circ} \mathrm{C}$ is found to be appropriate to reach the maximum of $1100 \mathrm{~m}^{2} / \mathrm{g}$ and $1080 \mathrm{mg} / \mathrm{g}$ during the $2 \mathrm{~h}$ of activation time. Increase in temperature may cause two main changes in the material: The first one is to form volatile material that is the result of dehydration and elimination reactions, the second one is to serve cross-linking structure that is an indication of the pore development and surface area. These changes gradually improve reactions between carbonaceous material and $\mathrm{KOH}$, and strongly depend on the intensity of the temperature applied. As reported in the literature, alkali metal atoms are removed from the intercalated system at higher temperature
[17], therefore the surface area and micropore volume may increase. As seen in Table 1, the Highest BET surface area and iodine number are found during the $8 \mathrm{~h}$ of impregnation time. These results were expected due to the raw material impregnated with $\mathrm{KOH}$ method for a long time. From the data in Table 1, it is obvious that the activation timeis essential to the activated carbon. Increasing the activation duration from 1 to $2 \mathrm{~h}$ is to blame for the increasing of BET surface area and iodine number to increase. However, the increase of the activation duration from 2 to $4 \mathrm{~h}$ results in a lower BET and iodine number of the activated carbon that longer duration of activation time caused some of the pores to enlarge or even collapse.

The adsorbent pores were classified into three groups: micropore (diameter $<2 \mathrm{~nm})$, mesopore $(2-50 \mathrm{~nm})$, and macropore $(>50 \mathrm{~nm})$. Pore size result shows that the activated carbon based reedy grass leaves mainly exhibits pores of diameter in the range of $2-3 \mathrm{~nm}$, where the pore sizes become predominantly micro and mesoporous.

Figure. 1 gives the $\mathrm{N}_{2}$ adsorption isotherms at $-196^{\circ} \mathrm{C}$ of the activated carbons produced at the activation temperature of $800 \mathrm{oC}$, under $\mathrm{N}_{2}$ atmosphere for $2 \mathrm{~h}$ of duration and $8 \mathrm{~h}$ of impregnation. According to IUPAC classification, the isotherm is of Type I, which represents dense micropore structures. The surface area and pore volume of activated carbon prepared under optimum conditions were $1100 \mathrm{~m}^{2} / \mathrm{g}$ and $0.601 \mathrm{~cm}^{3} / \mathrm{g}$ respectively. While the pore size was $2.1640 \mathrm{~nm}$.

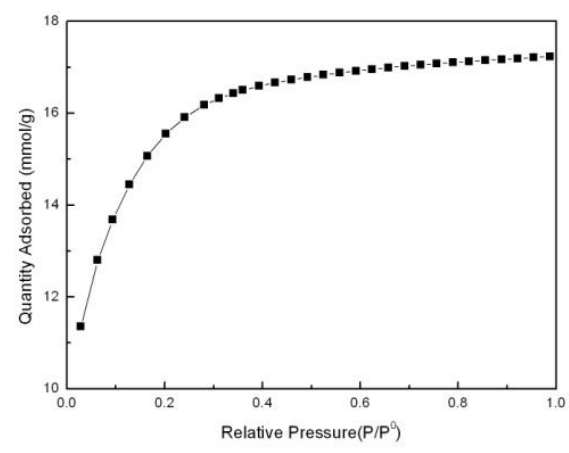

Figure 1. Nitrogen adsorption isotherm of produced activated carbon

TABLE I. EFFECT OF IMPREGNATION TIME, ACTIVATION TEMPERATURE, DURATION TIME ON THE AREA OF ACTIVATED CARBONS, VALUES OF PARAMETERS CHARACTERIZING POROUS STRUCTURE OF ACTIVATED CARBONS CALCULATED FROM THE NITROGEN ADSORPTION/DESORPTION ISOTHERMS AND IODINE NUMBERS.

\begin{tabular}{|c|c|c|c|c|c|c|}
\hline $\begin{array}{l}\text { Impregnation } \\
\text { times }(\mathrm{h})\end{array}$ & $\begin{array}{c}\text { Activation } \\
\text { temperature }\left({ }^{\circ} \mathrm{C}\right)\end{array}$ & $\begin{array}{l}\text { Duration time } \\
\text { (h) }\end{array}$ & Surface area $\left(\mathrm{m}^{2} / \mathrm{g}\right)$ & Micropore volume $\left(\mathrm{cm}^{3} / \mathrm{g}\right)$ & Pore size(nm) & Iodine number $(\mathrm{mg} / \mathrm{g})$ \\
\hline 8 & 650 & 2 & 530 & 0.264 & 2.1089 & 435 \\
\hline 8 & 700 & 2 & 559 & 0.294 & 2.1065 & 492 \\
\hline 8 & 750 & 2 & 931 & 0.492 & 2.1011 & 867 \\
\hline 8 & 800 & 2 & 1100 & 0.601 & 2.1640 & 1080 \\
\hline 8 & 800 & 1 & 978 & 0.508 & 2.1045 & 902 \\
\hline 8 & 800 & 3 & 815 & 0.421 & 2.1082 & 789 \\
\hline 8 & 800 & 4 & 744 & 0.381 & 2.0974 & 655 \\
\hline 6 & 800 & 2 & 745 & 0.382 & 2.1013 & 660 \\
\hline 10 & 800 & 2 & 980 & 0.509 & 2.1050 & 912 \\
\hline 12 & 800 & 2 & 982 & 0,510 & 2.1055 & 920 \\
\hline
\end{tabular}




\section{B. Thermogravimetric Analysis of the Raw Material}

Figure. 2 gives the results from TG analysis carried out on reedy grass leaves. The decomposition of reedy grass leaves takes place in three stages. The first stage that obtained at 35 to $200^{\circ} \mathrm{C}$ indicates the loss of adsorbed water was about $2.01 \%$. Volatile components and light gases such as $\mathrm{CO}$ and $\mathrm{CO}_{2}$ may also be released at this stage for the weight loss of the sample is higher than the moisture content of the raw reedy grass. In the second stage, sharp weight loss of the raw material was about $55.0 \%$ at 200 $-400^{\circ} \mathrm{C}$ in which carbonisation process begins and mainly hemicellulose and cellulose fractions decompose. The weight losses may be attributed to the major components (hemicellulose, cellulose and lignin fractions) decomposition of the raw reedy grass leaves. Nevertheless, above $600^{\circ} \mathrm{C}$, no significant weight loss is observed over $600^{\circ} \mathrm{C}$, indicating that $600{ }^{\circ} \mathrm{C}$ could be chosen for the preparation of the activated carbon.

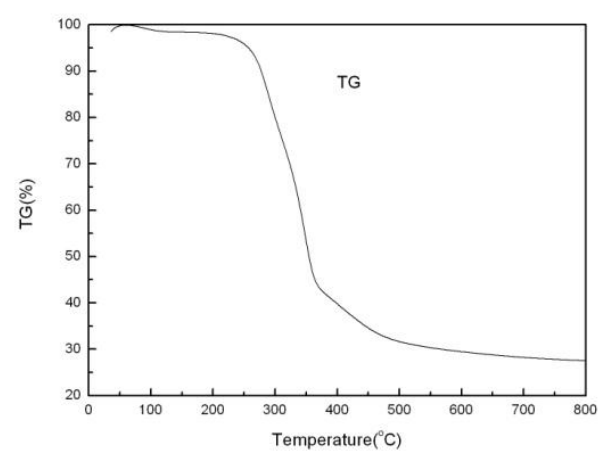

Figure 2. TG curves measured for reedy grass leaves

\section{Textural Characterization by SEM}

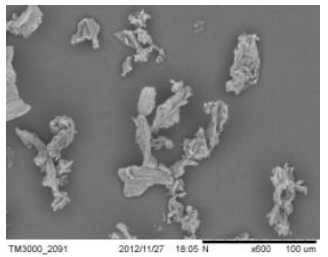

(a)

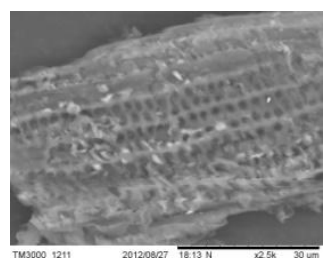

(b)
Figure 3. SEM micrographs obtained at various magnications from secondary electron of (a) $\times 600 \mathrm{AC},(\mathrm{b}) \times 2500 \mathrm{AC}$,

SEM images of some selected activated carbon samples are shown in Figure3a-b. It can be seen from the micrographs that the activated carbons have relatively heterogeneous with a few macropores. Figure $3 \mathrm{~b}$ shows a magnification of lamellar particles found at activated carbon that displays network arrangement of the macropores originating from the reedy grass leaves structure. It might be interpreted as chars soaked in a large amount of $\mathrm{KOH}$, a thin film of $\mathrm{KOH}$ should be coated on their surface and the interior of chars should be covered with $\mathrm{KOH}$ completely. During the activation in an inert atmosphere, surface pyrolysis does not occur on the surface of chars, resulting in the absence of a cottony structure. Consequently, the final activated carbons maintain the original structure features of chars. However, the soaking of $\mathrm{KOH}$ in the char interior still promotes the etching during the activation process, which creates micropores.

\section{Functional Groups of Reedy Grass Leaves Activated Carbon}

The FT-IR spectra of activated reedy grass leaves are shown in Figure4. The broad absorption band at 3300-3600 $\mathrm{cm}^{-1}$ with a maximum at about $3400 \mathrm{~cm}^{-1}$ is the characteristic of the stretching vibration of hydrogen bonded hydroxyl groups(from carboxyls, phenols or alcohols) and water adsorbed in the activated carbons. The band at $2800-3000 \mathrm{~cm}^{-1}$ indicates the presence of an aliphatic- $\mathrm{CH}$ stretching. The spectra of the prepared activated carbons also show a strong band at $1600-1580 \mathrm{~cm}^{-1}$ due to $\mathrm{C}-\mathrm{C}$ vibrations in aromatic rings. A broad band is observed in spectra in the main fingerprint spectral region between 1300 and $900 \mathrm{~cm}^{-1}$ with the maxima at $1038 \mathrm{~cm}^{-1}$. Broad band at $1000-1300 \mathrm{~cm}^{-1}$ is usually found with oxidized carbons and has been assigned to $\mathrm{C}-\mathrm{O}$ stretching in acids, alcohols, phenols, ethers and/or esters groups [18].

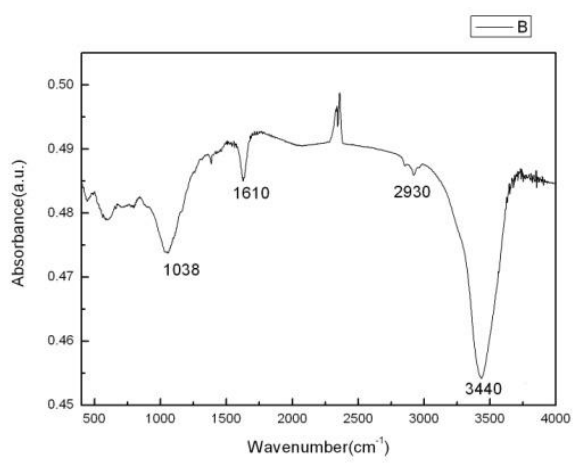

Figure 4. FTIR spectra of activated carbons

\section{CONCLUSIONS}

In the present study, Activated carbons were produced by $\mathrm{KOH}$,a kind of chemical activation at $650,700,750$, $800^{\circ} \mathrm{C}$ from chars that were carbonized from reedy grass leaves at $450^{\circ} \mathrm{C}$ in $\mathrm{N}_{2}$ atmosphere. The effects of activation temperature, duration time and impregnation time on the area of activated carbons were examined. With the increase of activation temperature, BET surface areas and iodine number of produced activated carbon were increased. The maximum surface area and iodine number of the $\mathrm{AC}$ were $1100 \mathrm{~m}^{2} / \mathrm{g}$ and $1080 \mathrm{mg} / \mathrm{g}$ for active carbons produced at activation temperature of $800^{\circ} \mathrm{C}$ with $2 \mathrm{~h}$ 's activation time and $8 \mathrm{~h}$ 's impregnation time.. The micropore volume of obtained activated carbon has $0.601 \mathrm{~cm}^{3} / \mathrm{g}$, pore size was $2.1640 \mathrm{~nm}$.

The various characterization methods used in this study show that reedy grass leaves might be a promising material for the preparation of a valuable activated carbon. 


\section{ACKNOWLEDGMENTS}

Authors thank the financial support from National Natural Science Foundation of China (Grant No. 21276059).

\section{REFERENCES}

[1] O. Ioannidou, A. Zabaniotou, Agricultural residues as precursors for activated carbon production-A review [J]. Renew. Sustain. Energy Rev. 2007,11(9):1966-2005

[2] M. Olivares-Marın, C. Fernandez-Gonza'lez,et al. Preparation of activated carbon from cherry stones by chemical activation with ZnCl2[J]. Applied Surface Science. 2006,252 : 5967-5971

[3] M. Ruiz-Fernández. M. Alexandre-Franco,et al. Development of activated carbon from vine shoots by physical and chemical activation methods. Some insight into activation mechanisms [J]. Adsorption . 2011,17 : 621-629

[4] Qiang Li,Yin Wang,Jian Yu,et al.Preparation and characterization of activated carbons from spirit lees by physical activation[J].New Carbon Materials 2012, 27(6): 440-447

[5] XinYang Wang,DanXi Li ,Bao Min Yang,etal. Textural Characteristics of Coconut Shell-Based Activated Carbons with Steam Activation[J].Advance Materials Research, 2012.12:366-373

[6] Min Song, Bao Sheng,Rui Xiao, etal. The comparison of two activation techniques to prepare activated carbon from corncob [J]. Biomass and Bioenergy, 2013. 48: 250-256

[7] M.Turmuzi,W.E.W.Daud, S.M.Tasirin,eta1. Production of activated carbons from candlenut shell by $\mathrm{C}_{2}$ activation [J]. Carbon, 2004, 42:453-455

[8] H.N. Cheng, Lynda H. Wartelle, K. Thomas Klasson. Solid-state NMR and ESR studies of activated carbons produced from pecan shells [J]. CARBON, 2010,48:2455 -2469

[9] Mustafa Özdemir, Tamer Bolgaz,et al. Preparation and characterization of activated carbon from cotton stalks in a two-stage process[J]. Journal of Analytical and Applied Pyrolysis .2011,92 $171-175$

[10] Y. Örkün;N. Karatepe and R. Yavuz. Influence of Temperature and Impregnation Ratio of H3PO4 on the Production of Activated Carbon from Hazelnut Shell. Acta Physica Polonica .Series A. 2012,121(1):277

[11] I. Kula, M. Ugurlu, H. Karaoglu, A. Celik, Adsorption of Cd(II) from aqueous solutions using activated carbon prepared from olive stone by $\mathrm{ZnCl} 2$ activation[J],Bioresource Technology, 2008,99: $492-501$.

[12] R.M. Suzuki, A.D. Andrade, J. C. Sousa, M. C. Rollemberg, Preparation and characterization of activated carbon from rice bran [J], Bioresource Technology, 2007,98: 1985 -1991.

[13] I.A. Rahman, B. Saad, S. Shaidan, E.S. Sya Rizal, Adsorption characteristics of malachite green on activated carbon derived from rice husks produc ed by chemical- thermal process[J], Bioresource Technology , 2005,96: 1578-1583.

[14] K.Y. Foo, B.H. Hameed,. Porous structure and adsorptive properties of pineapple peel based activated carbons prepared via microwave assisted $\mathrm{KOH}$ and $\mathrm{K}_{2} \mathrm{CO}_{3}$ activation [J]. Microporous and Mesoporous Materials. 2012,148 : 191-195

[15] M. Benadjemia, L. Millière, L. Reinert,et al. Preparation, characterization and Methylene Blue adsorption of phosphoric acid activated carbons from globe artichoke leaves[J]. Fuel Processing Technology, 2011,92: 1203-1212

[16] K.L. John, J.J. Vijaya, G. Sekaran, Effect of two-stage process on the preparation and characterization of porous carbon composite from rice husk by phosphoric acid activation[J], Ind. Eng. Chem. Res, 2004,43: 1832-1838.

[17] Mar sh H, Reinoso FR. Act ivated carbon. ISBN: 0080444636. Great Britain: Elsevier Science \&Technology Books; 2006.

[18] J. Zawadzki, Infr ared spectroscopy in surface chemistry of ethylene, in: P.A.Thrower (Ed.), Chemistry and Physics of Carbon, vol. 21, Marcel Dekker, New York, 1989, 147 -386. 